\title{
Home range size and patterns of space use by lingcod, copper rockfish and quillback rockfish in relation to diel and tidal cycles
}

\author{
N. Tolimieri ${ }^{1, *}$, K. Andrews ${ }^{1}$, G. Williams ${ }^{1}$, S. Katz ${ }^{1,2}$, P. S. Levin ${ }^{1}$ \\ ${ }^{1}$ NOAA Fisheries, Northwest Fisheries Science Center, 2725 Montlake Blvd E, Seattle, Washington 98112, USA \\ ${ }^{2}$ Present address: Channel Islands National Marine Sanctuary, 113 Harbor Way, Suite 150, Santa Barbara, California 93109, USA
}

\begin{abstract}
The estimation of home range size of marine fish has received attention because of its application to the design of marine reserves. How individuals use space may also be important to the management of the species and for understanding behavioral processes like optimal foraging or territoriality. We used an acoustic tracking system (VRAP) to examine patterns in home range size and movement behavior for 3 demersal fishes in Puget Sound: lingcod Ophiodon elongatus, copper rockfish Sebastes caurinus and quillback rockfish S. maliger. Data were collected over 8 wk in the summer of 2006 and $3 \mathrm{wk}$ in the winter of 2007 . Home ranges were relatively small $\left(\sim 1500\right.$ to $\left.2500 \mathrm{~m}^{2}\right)$ and did not differ among species. During the summer, lingcod had larger home ranges during the day than at night. Movement in all 3 species was in some way related to diel and tidal cycles, although individuals within species differed, and there was no general pattern. About half of the lingcod used portions of their home ranges only during the day and on the flood tide. Other individuals made similar movements on the ebb tide. Some copper rockfish moved to specific areas of their home range on the day ebb tide, while others made these movements on the night flood tide; others showed no pattern. Similar results were seen for quillback rockfish. While the arena of resource management often requires us to simplify complex systems, our results illustrate that such simplification may be difficult, and will depend ultimately on detailed behavioral data.
\end{abstract}

KEY WORDS: VRAP · Acoustic tracking $\cdot$ Rockfish $\cdot$ Lingcod $\cdot$ Home range

Resale or republication not permitted without written consent of the publisher

\section{INTRODUCTION}

As ecosystem approaches to managing marine fisheries are adopted, it is becoming increasingly necessary to consider spatial aspects of population dynamics. Rational design of networks of marine protected areas (MPAs) requires an understanding of the relationship between the spatial extent of a reserve, home ranges of fish, and resource distribution. As a result, understanding movement patterns of fishes is of central importance to measuring MPA effectiveness. In part, this is due to 2 potentially conflicting objectives of MPAs: (1) to conserve a breeding stock, adult movement out of MPAs should be minimal, but (2) to augment local fisheries, some flux outside the MPAs to harvested areas is desirable, i.e. 'spillover' (Zeller \& Russ 1998, Kramer \& Chapman 1999, Cole et al. 2000).

Well-defined home ranges appear to be common among the coral- and rocky-reef associated fish species that MPAs are typically intended to protect (Matthews 1990b, Kramer \& Chapman 1999, Lowe et al. 2003, Topping et al. 2005). For these fishes, home range area can vary considerably among species targeted by fishers from as little as $<10 \mathrm{~m}^{2}$ for some rockfishes in high relief habitat (Matthews 1990c) to over $55000 \mathrm{~m}^{2}$ for New Zealand snapper Pagrus auratus (Sparidae) (Parsons et al. 2003). There can also be considerable variation within species in home range area based in particular on type or shape of habitat (Matthews 1990c, Topping et al. 2005). 
Examining how individuals use space can reveal the diversity of behaviors within a species. Such diversity may be important for management of species and for understanding basic behavioral ecological processes such as optimal foraging, predator avoidance, habitat preference, shelter use, territoriality, reproductive behavior, etc. (Fretwell \& Lucas 1969, Fretwell 1972, Kramer \& Chapman 1999, Parsons et al. 2003, Austin et al. 2004, Morgan \& Kramer 2004, Lindholm et al. 2007). In species like New Zealand snapper Pagrus auratus (Willis et al. 2001, Willis \& Millar 2005) and possibly lingcod Ophiodon elongatus (Jagielo 1990), some portion of the population makes annual onshore/offshore migrations potentially reducing the effectiveness of reserves as these individuals move out of the unfished area. At smaller spatial scales, individuals within the same species may use their home ranges differently. For example, in the sparid Salpa salpa, some individuals have separate diurnal and nocturnal areas of residence while others do not (Jadot et al. 2006). In other species, diel patterns are more general with all individuals seeking shelter at night (Topping et al. 2005, Jorgensen et al. 2006).

We examined movement and home range sizes of 3 temperate fish species: lingcod Ophiodon elongatus (Hexagrammidae), copper rockfish Sebastes caurinus (Sebastidae) and quillback rockfish S. maliger (Sebastidae). All 3 species are demersal and generally associated with rocky reefs (Eschmeyer et al. 1983, Love et al. 2002). Lingcod are found from the Gulf of Alaska to Baja California from the intertidal to $475 \mathrm{~m}$ depth (Allen \& Smith 1988). Lingcod are generally resident on rocky reefs but do occasionally leave specific sites for periods of up to $2 \mathrm{wk}$ (Starr et al. 2004). They can disperse more than $50 \mathrm{~km}$ over the course of several years, although most stay within $8 \mathrm{~km}$ of their initial tagging site (Jagielo 1990). Their dispersal rates are high enough that in areas like the Strait of Georgia they can be considered a single stock (Smith et al. 1990). Copper rockfish are found from central Baja California to the northern Gulf of Alaska from barely subtidal waters to $183 \mathrm{~m}$ depth (Love et al. 2002). Quillback rockfish are found from central California to Alaska and occur from subtidal to $274 \mathrm{~m}$ depth (Love et al. 2002). These 2 rockfish species are among the most common rockfish in Puget Sound in the nearshore (Love et al. 2002). Copper and Quillback rockfish have been the subjects of previous tracking studies in Puget Sound (Matthews et al. 1986, Matthews 1990a,b,c). On complex, high relief reefs they tend to have home ranges as small as $10 \mathrm{~s}$ of $\mathrm{m}^{2}$ while on low relief reef their home ranges are much larger, though still relatively small $\left(4000 \mathrm{~m}^{2}\right)$. Historically, all 3 species have been important components of the nearshore recreational fishery in Puget Sound. Copper and Quillback together averaged $71.3 \%$ of the total recreational rockfish catch in Puget Sound from 1980 to 1999 (Data from the National Marine Fisheries Service, Fisheries Statistics and Economics Division, Silver Spring, MD; Marine Recreational Fisheries Statistics Survey, www.st.nmfs.gov/st1/; pers. comm.)

However, overexploitation has resulted in severe restrictions on fishing. At present, the lingcod fishery is limited to 1 May to 15 June, and there is a one/first fish bag limit for rockfish from 1 May to 30 September in some areas of Puget Sound, but in much of the Sound, rockfish can be taken only during lingcod season (WDFW 2007).

In this study, we used high-resolution ultrasonic telemetry to examine patterns of space use and movement of lingcod Ophiodon elongatus, copper rockfish Sebastes caurinus and quillback rockfish $S$. maliger. Specifically, we investigate the degree to which environmental variables (e.g. season, diel phase, or tidal phase) influence use of space and patterns of movement. For the copper and quillback rockfish, the basic calculation of home range to some extent replicates previous work (Matthews 1990c, b). However, our work has larger sample sizes and includes a detailed analysis of individual movement.

\section{MATERIALS AND METHODS}

Study site. We conducted all field-work for this study at the southern end of Whidbey Island in Puget Sound $\left(47^{\circ} 54.308^{\prime} \mathrm{N}, 122^{\circ} 26.072^{\prime} \mathrm{W}\right)$ (Fig. 1). The study area ranges in depth from approximately 8 to $19 \mathrm{~m}$ chart datum with $3 \mathrm{~m}$ tides. This site is primarily low relief sandstone composite with strong east-west tidal flow of at least $1.4 \mathrm{~m} \mathrm{~s}^{-1}$ (2.7 knots, measured with acoustic Doppler current profiler; N. Tolimieri unpubl. data). In the approximate center of the study area and running from the southwest to the northeast, there is an uplifted ridge, which ranges in height from ca. $10 \mathrm{~cm}$ to as much as $8 \mathrm{~m}$ (Fig. 1). This ridge is the primary physical structure in the study area. Although not visible on the multibeam map in Fig. 1, a cave-like area several meters deep extends horizontally under the eastern, uplifted side of the ridge. The higher, eastern fringe of the uplifted area generally supports brown macroalgae Pterygophora californica and Agarum fimbriatum from the ridge margin to ca. $10 \mathrm{~m}$ to the east in the shallower areas. Small rocks (up to $\sim 0.3 \mathrm{~m}$ diameter) and several large boulders ( 2.0 m diameter) are scattered throughout the area, especially to the east. To the northwest and just out of the VRAP buoy triangle (Fig. 1) is a depression approximately 2 to $3 \mathrm{~m}$ deeper than the surrounding area.

Tagging and tracking methodology. SCUBA divers caught all fish at approximately 15 to $20 \mathrm{~m}$ depth using 


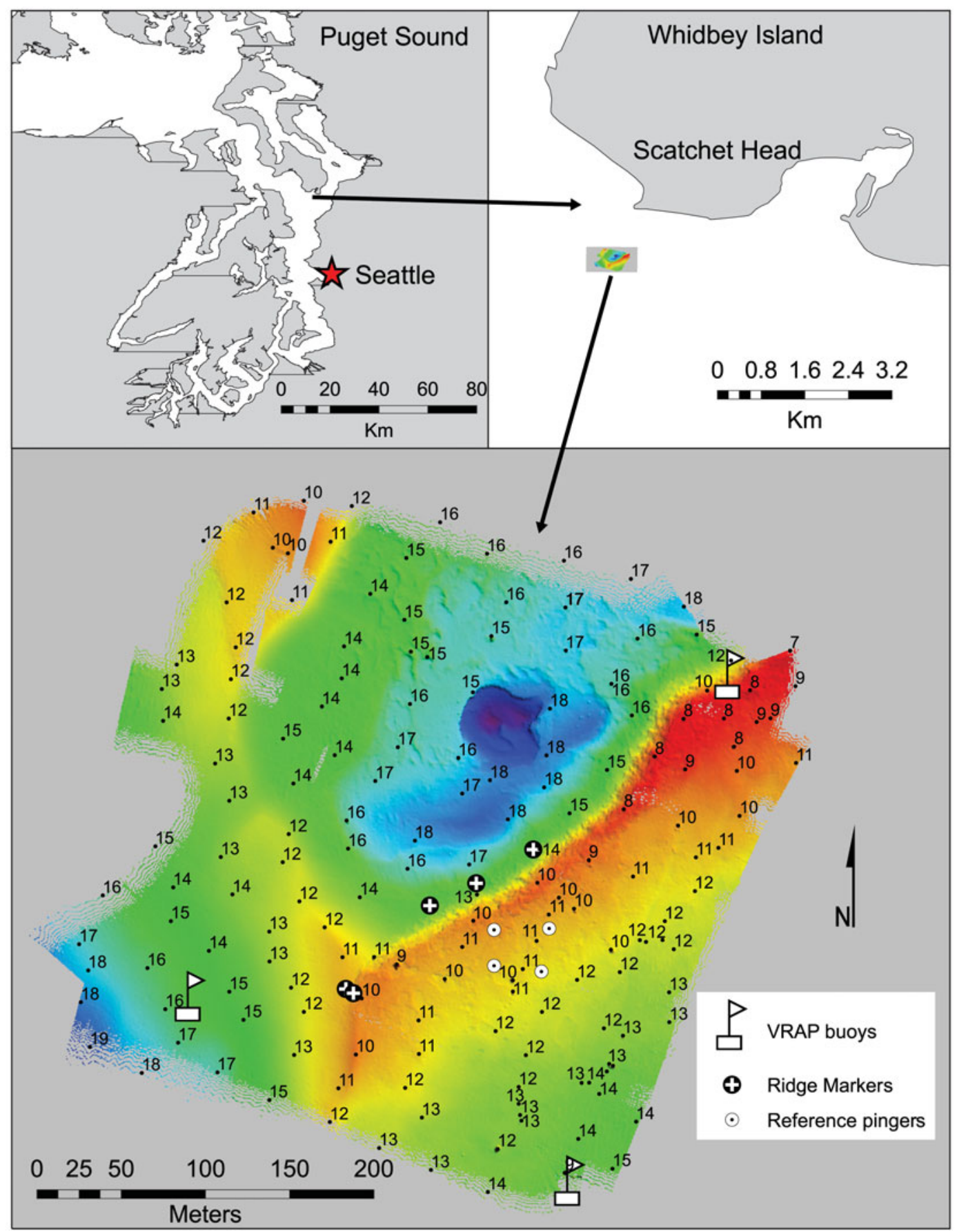

Fig. 1. Multibeam bathymetric map showing the ridge line and location of the VRAP sonobuoys, ridge markers and reference pingers. Ridge markers refer to pingers placed along the ridge line. Reference pingers were used to correct fish positions for buoy swinging due to tides. Numbers: depth soundings (m)

large hand nets (lingcod Ophiodon elongatus, copper rockfish Sebastes caurinus and quillback rockfish $S$. maliger). Individuals were placed in a wire mesh enclosure ( 2 to 4 per enclosure), brought slowly to the surface to minimize barotraumas (for the rockfishes), and then moved to holding containers aboard prior to surgery. aboard prior to surgery. To insert an acoustic
$\operatorname{tag}\left(\mathrm{VEMCO}{ }^{\circledR}, \mathrm{V} 13,13 \mathrm{~mm}\right.$ diameter, $36 \mathrm{~mm}$ length, weight: $12 \mathrm{~g}$ in air, $6 \mathrm{~g}$ in water; 20 to $60 \mathrm{~s}$ random on/off time, power output: $150 \mathrm{~dB}$ re $1 \mu \mathrm{Pa}$ at $1 \mathrm{~m}$ ), an individual was placed on its back (i.e. dorsal side down) in a chamois-lined, v-shaped foam 'bed', which was placed within a larger, water filled plastic container to allow for irrigation of the gills during surgery. 
After approximately $1 \mathrm{~min}$ in this position, the fish entered a state of tonic immobility (Henningsen 1994, Holland et al. 1999, Wells et al. 2005) and became nonresponsive. A small 2 to $3 \mathrm{~cm}$ long incision was made anterior of the anus and the acoustic tag inserted. The incision was closed using either surgical thread or surgical staples. We used surgical thread on the rockfish because the size and prevalence of scales made staples difficult to use. We used surgical staples for the lingcod because their smoother skin did not interfere with staple use, and because we were able to close the incision wounds more rapidly with staples. A Floy ${ }^{\circledR} \operatorname{tag}($ Floy Tag \& Mfg., Seattle) was inserted into the epaxial musculature to allow for external identification of individuals if necessary. Individuals were then placed in a separate holding container until they regained equilibrium (5 to $10 \mathrm{~min}$ ) after which they were returned to the water in the general vicinity of their capture.

We monitored fish movements using VEMCO's ${ }^{\circledR}$ Radio Acoustic Positioning system (VRAP, VEMCO, Nova Scotia). The system consists of 3 radioacoustic buoys (VRAP buoys), and a computer controlled base station. The positions of the acoustic tags ('pingers') are calculated via triangulation of the arrival times of the tag signal at the 3 buoys (VEMCO 2003). Once deployed the VRAP system monitors fish position at a potential scale of 1 to $2 \mathrm{~m}$ precision with relocations received at a time scale of minutes (O'Dor et al. 1998). We used the locations of 5 acoustic tags placed in the array to mark the ridge line to estimate the system precision near the center of the array. The SD in the locations for these 5 pingers over $3 \mathrm{~d}$ was $2.6 \mathrm{~m}$ on the $x$ axis and $3.3 \mathrm{~m}$ on the $y$-axis. Error is least in the middle of the VRAP triangle and increases quickly as one moves outside (VEMCO 2003). In particular it becomes large directly behind the buoys. Most of our tracks were near the center of the VRAP array. While there are portions of some home ranges that are outside the triangle (see 'Results'), we feel that the accuracy is sufficient for the hypotheses tested here. The rate at which fish locations are recorded is dependent upon a number of factors including the ping rate of the tag, interference between tags, background acoustic noise and interference with the habitat (VEMCO 2003).

Individuals were monitored for approximately $8 \mathrm{wk}$ during summer 2006 (31 July to 25 September) and 3 weeks during winter 2007 (9 to 28 February). As battery life of the VRAP buoys was ca. $10 \mathrm{~d}$ the study required 5 deployments in summer 2006 (31 July7 Aug, 14 Aug-26 Aug, 28 Aug-5 Sept, 5 Sept-9 Sept, 14 Sept-25 Sept) and 2 in winter 2007 (9 Feb-16 Feb, 16 Feb-28 Feb).

The 3 VRAP buoys were moored in place using two $90 \mathrm{~kg}$ concrete blocks at the end of 30 to $40 \mathrm{~m}$ of mooring line. Strong tidally driven currents (primarily east-west) produced large movements of the buoys at the surface over the tidal cycle (ca. $30 \mathrm{~m}$ ). The relative positions of the buoys at the surface create a relative coordinate system in which the tagged fish are located. As the buoys shift with the tidal flux, the VRAP coordinate system also shifts relative to the fixed coordinate system that one might measure with GPS. To correct for tidal movements of the VRAP buoys and the coordinate system they define, we placed 4 fixed pingers in known locations on the bottom (Fig. 1). These were deployed in a square ca. $30 \mathrm{~m}$ apart on a side. When post-processing the data, fish locations were calculated relative to the most recent fixed pinger location. Specifically, we first calculated the position (the mean of the locations) of the fixed pingers during the initial few hours of each deployment when the position of the surface buoys was known (measured with a GPS) and before the tide changed. The apparent displacement from this initial mean position was then calculated for each fixed pinger location. Fixed pinger locations that were clearly erroneous based on trilateration with the other fixed pingers, or did not follow the tidal cycle, were excluded. The most recent displacement was then subtracted from each fish location. Fish locations received more than $10 \mathrm{~min}$ from the most recent fixed pinger location were excluded from the data set. The apparent movement of the fixed pingers was also used to define the time of change in tidal currents at the site so that fish behavioral patterns could be compared in relation to ebb, slack and flood tides.

Home range and core area. Home range is the area generally used by an individual during normal activities like food gathering and does not imply territoriality (Burt 1943). It is commonly defined as the area in which an individual spends $95 \%$ of its time (e.g. Anderson 1982, Parsons et al. 2003, Jadot et al. 2006, Katajisto \& Moilanen 2006). The core area is an area of more intense use often defined as the area in which an individual spends $50 \%$ of its time (e.g. Jadot et al. 2006). We do not calculate a general home range based on all of the data for an individual. Instead we calculate home range for specific periods such as 'summer' home range or 'diurnal' home range. In these instances, home range refers to where an individual spent $95 \%$ of its time during that time period, e.g. diurnal, nocturnal, winter, summer. Thus summer home range would be the area where an individual spent $95 \%$ of its time during the summer sampling period; 'diurnal home range' would represent where an individual spent $95 \%$ of its time during the day ignoring data from other time periods. We use the term 'activity space' when referring to a portion of a fish's home range used during a particular time period but for which we did not actually calculate a home range. 
We calculated core area and home range based on the 50 and $95 \%$ kernel utilization density distributions (UD) respectively (Worton 1989, Katajisto \& Moilanen 2006). Kernel UDs provide a probabilistic measure of space use. With standard kernel UD methods, the relocation data need to be regularly spaced in time. However, relocation data from the VRAP system are irregularly spaced in time because of a number of factors including the random ping rate of the tag, interference between tags, and behavior of the fish in relation to the habitat. To account for spatial and temporal autocorrelation in the data, we used spatiotemporal kernel methodology (Katajisto \& Moilanen 2006), which accounts for temporal aggregation of observations by weighting observations based on their proximity in time and in space. Observations close in time are given less weight unless they are also distant in space. We calculated the 50 and $95 \%$ UD for fishes using the program B-Range (available at: www.helsinki.fi/science/ metapop/). The calculation requires choosing both the space kernel $\left(h_{\mathrm{s}}\right)$ and time kernel $\left(h_{\mathrm{t}}\right)$. Choice of these values should be based on the biology of the species, the accuracy of the location measurements and the desired spatial resolution of the estimate (Katajisto \& Moilanen 2006). We first calculated $h_{\text {opt }}$ (also refered to as $h_{\text {ref }}$ ) - an ad hoc but simple and effective method of producing a reference value for $h_{\mathrm{s}}$-from the distribution of the data (Bowman 1985, Worton 1989). Median $h_{\text {opt }}$ across all individuals was 3.89. We also examined the $\mathrm{SD}$ in the locations of 5 pingers placed in the array for $3 \mathrm{~d}$ to mark the ridge line $\left(\mathrm{SD}_{\mathrm{x}}=2.6, \mathrm{SD}_{\mathrm{y}}=3.3\right)$. Because $h_{\text {opt }}$ tends to over-smooth when the distribution is not bivariate-normal, we set $h_{\mathrm{s}}$ at 3.0. We allowed the B-Range program to choose $h_{\mathrm{t}}$ based on $h_{\mathrm{t}}\left(\mathrm{N}_{\text {min }}\right.$ ) (where $\mathrm{N}_{\text {min }}$ is the minimum effective number of observations) above which all observation become correlated to some degree (Katajisto \& Moilanen 2006). Unless otherwise specified, we use 'home range' to refer to the $95 \%$ UD calculated using the spatiotemporal kernel method.

We used linear mixed models (LMMs; Littell et al. 1996, Verbeke \& Molenberghs 1997, McCullagh \& Searle 2001) to make a number of comparisons among home range sizes, among species and within species at different times, e.g. winter versus summer or night versus day. We chose LMMs because they allowed us to account for and specifically estimate autocorrelation due to repeated measures on individuals and as well as directly estimate variance, i.e. assume heterogeneity of variance (Littell et al. 1996, McCullagh \& Searle 2001). Choice of covariance parameters and autocorrelation structures was based on comparing Akaike's Information Criteria (AIC) among candidate models. We evaluated either first-order autocorrelation when there was only 1 time step between observations (e.g. winter ver- sus summer) or an unstructured covariance structure where there were 3 time periods without an obvious order (e.g. night, crepuscular, day). We assessed the normality of the residuals for all models using QQplots and Kolmogrov-Smirnov tests. Further details of statistical comparisons are given in the results.

Behavioral patterns in relation to diel phase, tide, and season. To better examine behavioral patterns, we examined activity spaces for each fish in relation to diel phase (day, crepuscular, night), tidal period, deployment within season and deployment between seasons (winter versus summer). For diel phase, the crepuscular period was defined as $1 \mathrm{~h}$ from sunrise or sunset. Deployment within season was an arbitrary classification based on when the VRAP positioning buoys were replaced because of low battery power. Thus there were 5 'deployments' in 2006 and 2 in 2007 (see 'Methods') lasting an average of $8.7 \mathrm{~d}$ (range: 4 to $12 \mathrm{~d}$ ). Coverage was not continuous in the summer primarily due to power losses at the onshore base station.

We defined a number of characteristics of each fish's behavior and home range. First we determined whether a fish had single or multiple core areas. A fish could have $>1$ core area if there were geographically distinct portions in its $50 \%$ UD. An individual had a 'nocturnal', 'diurnal' or 'crepuscular' activity space if it used a particular portion of its summer 95\% UD exclusively or primarily during one of those periods. We then examined this space use in relation to the tidal cycle (ebb, flood, slack). Between deployments within the summer and between summer and winter, we determined whether the above behaviors changed as well as whether the home range shifted in location or the fish was absent for long periods of time.

\section{RESULTS}

\section{Core area and home range size}

We tagged a total of 24 fish between 06 July and 15 August 2006: 6 copper rockfish, 8 quillback rockfish and 10 lingcod. Of these, 2 copper and 2 quillback rockfish disappeared prior to the deployment of the VRAP system and were never recorded (2 copper and 2 quillback). One lingcod and 1 quillback were recorded for only 1 to 2 days following their initial tagging and then were no longer recorded in the array. These 6 fishes were excluded from the analyses. For this study we followed 18 fishes starting 31 July 2006: 4 copper rockfish, 5 quillback rockfish and 9 lingcod. Of these, all 4 copper rockfish were recorded in the array in February of 2007 . Four of the 5 quillback and 5 of the 9 lingcod were also recorded in the array as of the February 2007 deployments. 
We wanted to compare home range size in the winter to that in the summer, but the overall length of the winter (ca. $3 \mathrm{wk}$ ) and the summer (ca. $8 \mathrm{wk}$ ) sampling periods differed. Therefore, we first tested whether the length of the sampling period in the summer affected the estimate of home range size. We calculated home ranges for the $3 \mathrm{wk}$ period of the summer that corresponded to the same portion of the lunar cycle for the 3 wk of winter sampling. We then compared these home ranges to the ones estimated from the full $8 \mathrm{wk}$ sample. The length of the summer sampling period did not affect home range size (LMM, 'Period' and 'Species' as main effects, first order autocorrelation, $\rho=0.98$; Period effect: $F_{1,15}=1.91, \mathrm{p}=0.19$ ). Therefore, we used the home ranges estimated based on the full $8 \mathrm{wk}$ summer deployment in the winter-summer comparison.

The mean size of a fish's core area (the $50 \%$ UD) differed among species and seasons (LMM, species $\times$ season, $\left.F_{2,25}=3.47, \mathrm{p}=0.047\right)$ and overall variance $\pm \mathrm{SE}$ was higher in the summer $\left(49724 \pm 18157 \mathrm{~m}^{2}\right)$ than in the winter $\left(7931 \pm 3547 \mathrm{~m}^{2}\right)$. This result was driven by lingcod, which had larger core areas in the summer than in the winter (Tukey's test, $\mathrm{p}=0.036$, Table 1). There was no overall difference among species $\left(F_{2,25}=\right.$ 1.07, $\mathrm{p}=0.36)$ nor among seasons $\left(F_{1,25}=1.72, \mathrm{p}=0.20\right)$ in mean size of the $50 \%$ UD. Autocorrelation was not important to the model fit.

Home range size (95\% UD) did not differ between seasons (Table $1, F_{1,25}=2.471, \mathrm{p}=0.12$ ) or among species (LMM, $\left.F_{2,25}=0.56, \mathrm{p}=0.58\right)$, and there was no interaction between the main effects $\left(\mathrm{LMM}, F_{2,25}=\right.$ 2.06, $\mathrm{p}=0.15$ ). However, variance $\pm \mathrm{SE}$ in home range was much higher in the summer $(2547478 \pm$ $\left.930207 \mathrm{~m}^{2}\right)$ than in the winter $\left(315343 \pm 141026 \mathrm{~m}^{2}\right)$. Autocorrelation was not important to model fit.

We next analyzed patterns in home range size among diurnal, nocturnal and crepuscular periods separately for each species. In these analyses, diel phase and season were the main effects in the LMM. Model fitting evaluated heterogeneous variances and an unstructured autocorrelation structure for the variance-covariance matrix. For lingcod, home range size differed among diel periods $\left(F_{2,26}=6.36, \mathrm{p}=0.0056\right)$ and seasons $\left(F_{1,13}=7.34, \mathrm{p}=0.0018\right)$ and there was a significant interaction $\left(F_{2,26}=6.16, p=0.0065\right)$ (Fig. 2a,b). During the summer (Fig. 2a), home range was greater during the day than at night (TukeyKramer test, $p=0.038$ ), and in the winter (Fig. 2b) crepuscular home range was smaller than the diurnal $(\mathrm{p}=$ $0.04)$ or nocturnal $(p=0.01)$ one. Crepuscular home range was lower in the winter than the summer $(\mathrm{p}=$ 0.016). The best model fit was achieved with an unstructured variance covariance matrix grouped by season. That is, there was autocorrelation between the diel periods, but levels of autocorrelation and variance
Table 1. Ophiodon elongatus, Sebastes caurinus and S. maliger. Home ranges $\left(\mathrm{m}^{2}\right)$ during an $8 \mathrm{wk}$ summer deployment and a 3 wk winter deployment expressed as 50 and $95 \%$ utilization distributions (UD). UDs were calculated using a spatio-temporal kernel method (Katajisto \& Moilanen 2006). Means and SEs are model output from linear mixed models (Species $\times$ Seasons, run separately for the 50 and $95 \%$ UDs). SL: standard length

\begin{tabular}{|lrrrcc|}
\hline \multirow{2}{*}{ ID } & SL & \multicolumn{2}{c}{ Summer } & \multicolumn{2}{c|}{ Winter } \\
& & $50 \%$ & $95 \%$ & $50 \%$ & $95 \%$ \\
\hline Lingcod & & & & & \\
13 & 63 & 234 & 900 & 189 & 1080 \\
15 & 55 & 513 & 1584 & - & - \\
16 & 57 & 675 & 3573 & 108 & 495 \\
17 & 50 & 918 & 3888 & - & - \\
32 & 47 & 648 & 2952 & - & - \\
35 & 68 & 369 & 1953 & 342 & 1944 \\
44 & 65 & 729 & 2790 & 162 & 603 \\
741 & 49 & 135 & 684 & 306 & 1575 \\
745 & 45 & 225 & 1044 & - & - \\
Mean & & 494 & 2820 & 221 & 1139 \\
SE & & 74 & 532 & 39 & 251 \\
Copper rockfish & & & & \\
11 & 35 & 171 & 630 & 315 & 1755 \\
18 & 33 & 198 & 783 & 333 & 1683 \\
46 & 36 & 477 & 2628 & 234 & 1602 \\
49 & 30 & 594 & 5751 & 378 & 2430 \\
Mean & & 360 & 2448 & 315 & 1868 \\
SE & & 111 & 798 & 44 & 280 \\
Quillback rockfish & & & & \\
14 & 32 & 135 & 621 & - & - \\
34 & 26 & 108 & 612 & 351 & 2169 \\
41 & 29 & 243 & 2475 & 396 & 2196 \\
47 & 30 & 351 & 2394 & 270 & 1593 \\
48 & 32 & 261 & 1215 & 171 & 864 \\
Mean & & 220 & 1463 & 297 & 1706 \\
SE & & 99 & 713 & 44 & 280 \\
& & & & & \\
\hline
\end{tabular}

were higher in the summer than in the winter (results not shown).

For copper rockfish, there was no effect of diel phase on home range size (Fig. 2, $F_{2,18}=1.85, \mathrm{p}=0.19$ ); there was no difference among seasons $\left(F_{1,18}=0.76, \mathrm{p}=\right.$ $0.39)_{i}$ and there was no interaction between main effects $\left(F_{2,18}=0.13, \mathrm{p}=0.88\right)$. While there were no overall differences in mean home range size, the best model fit was achieved by estimating separate variances by season and period. The highest variance was seen during summer nocturnal periods and variance in home range size was much lower in the winter than in the summer overall. Autocorrelation was not important to the model fit. Home range size for quillback rockfish did not differ among diel phase (Fig. 2, $F_{2,21}=2.14, \mathrm{p}=$ $0.14)$, or seasons $\left(F_{1,21}=1.02, \mathrm{p}=0.32\right)$, and there was no interaction $\left(F_{2,21}=0.09, \mathrm{p}=0.92\right)$.

Neither winter nor summer home range size was correlated with body size for any of the 3 species for both 


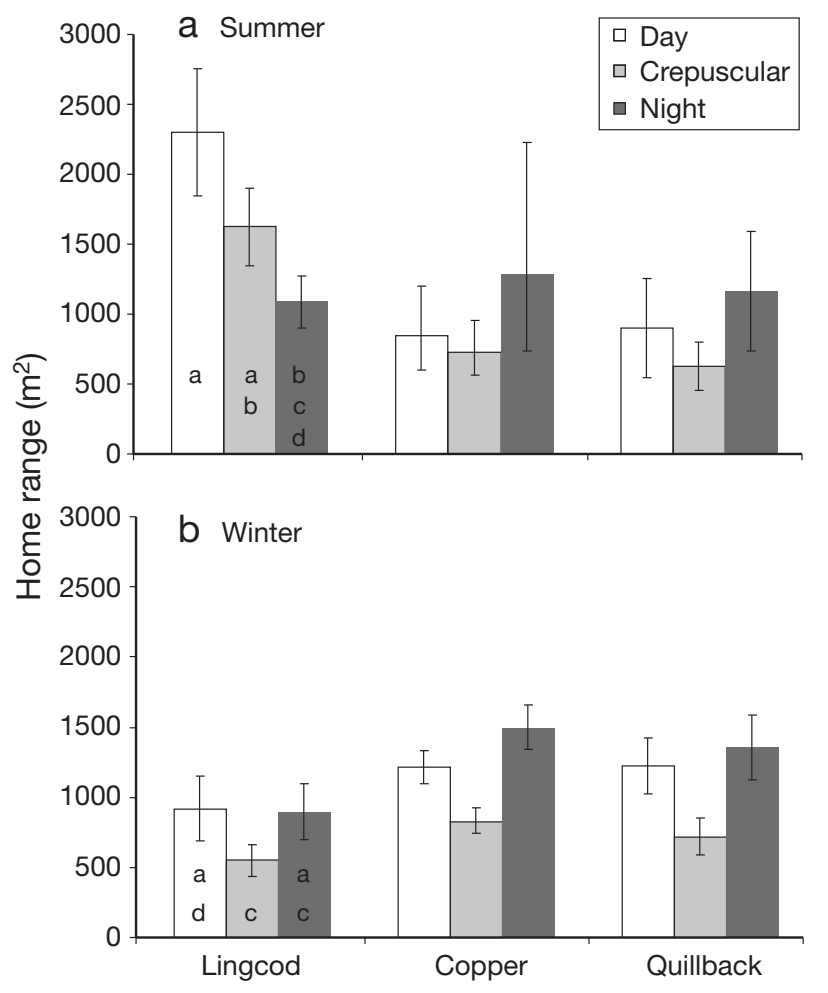

Fig. 2. Ophiodon elongatus, Sebastes caurinus and S. maliger. Mean home range size for diel period in (a) summer and (b) winter. Data are the $95 \%$ utilization distribution for that time period calculated using a spatio-temporal kernel. Error bars: \pm 1 SE. For lingcod, letters indicate home ranges that could not be distinguished statistically (Tukey-Kramer test $p>0.05)$. No differences were found for copper and quillback; comparisons were not made among species

the $50 \%$ UD and the $95 \%$ UD ( $p>0.5$ in all cases). However, given the small sample sizes, especially for the rockfishes, this result should not be over-interpreted.

\section{Behavior patterns in relation to diel phase, tide and season}

For most individuals the ridge appeared to represent an important boundary (Fig. $3 \& 4$ ). Most of the lingcod operated primarily on one side of the ridge (Fig. 3), as did all of the copper rockfish (Fig. 4a,b), although the side varied among individuals for both species. Four of the 5 quillback rockfish operated almost exclusively to one side of the ridge boundary (Fig. 4c,d). Those fish that did move across the uplifted ridge tended to do so in the southwestern section where there was less of a difference in depth between the east and west side of the ridge. At the peak of tidal flow, vertical velocities above the ridge can reach $0.30 \mathrm{~m} \mathrm{~s}^{-1}$ (measured with

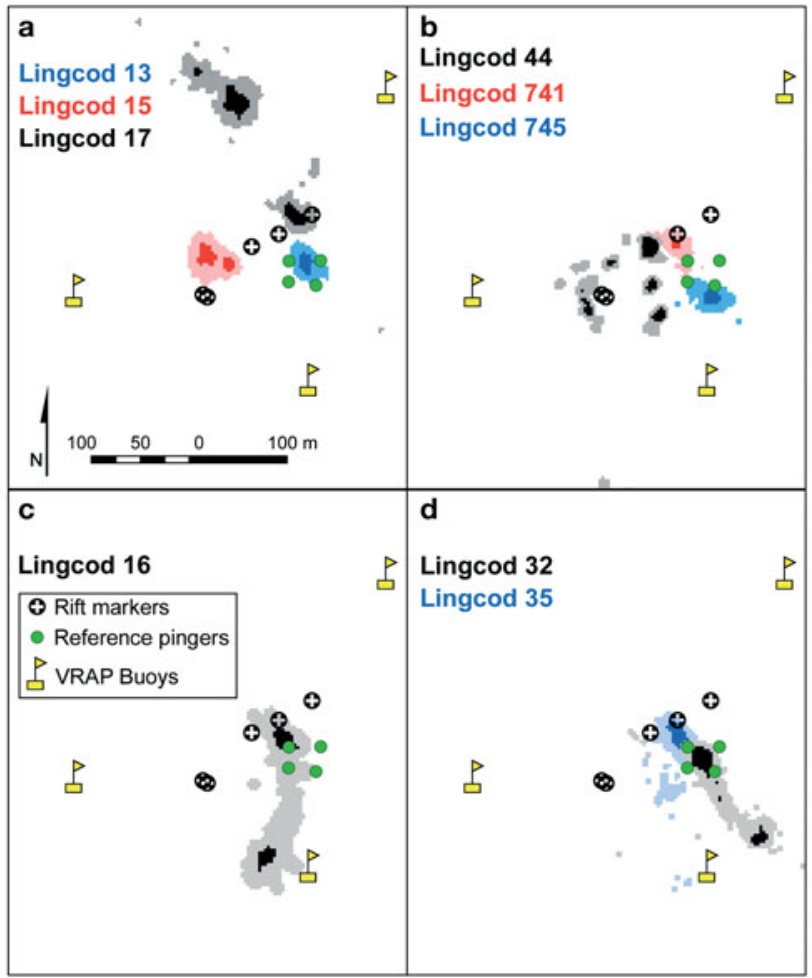

Fig. 3. Ophiodon elongatus. Summer (8 wk) home range for the 9 lingcod tagged in the study. For each fish, the darker shade is the $50 \%$ utilization distribution (UD); the lighter shade represents the $95 \%$ UD

Acoustic Doppler Current Profiler; N. Tolimieri pers. obs.) with a curtain of turbulent eddies that reach the surface. In this location it seems likely that hydraulic structures may reinforce observed behavioral boundaries set by physical habitat.

Five of the 9 lingcod and 2 of the 5 quillback rockfish had $>1$ core area during the summer (Table 2, Figs. $3 \&$ $4 \mathrm{c}, \mathrm{d})$. None of the copper rockfish had $>1$ core area (Fig. 4a,b). For most of the fish with multiple core areas (1 of the 2 quillback, and all the lingcod), at least one was used either primarily nocturnally or diurnally and generally on a specific tide (Fig. 5). Five of the 9 lingcod had areas of their home range that they utilized primarily or exclusively during the day, although there was generally some crepuscular presence in these areas as well. Four of the 5 moved to these diurnal activity spaces on the daytime flood tide, while the fifth moved on the ebb tide. For example, lingcod 16 (Fig. 5a) and lingcod 32 (Fig. 5b) both made daily movements from the area of the ridge to other areas approximately $150 \mathrm{~m}$ distant. In the summer, the area of the ridge was occupied during all periods (day, crepuscular, night), but the areas distant from the ridge were occupied generally only during daylight hours on a flood tide (Fig. 6a,b). Fish made repeated daily move- 


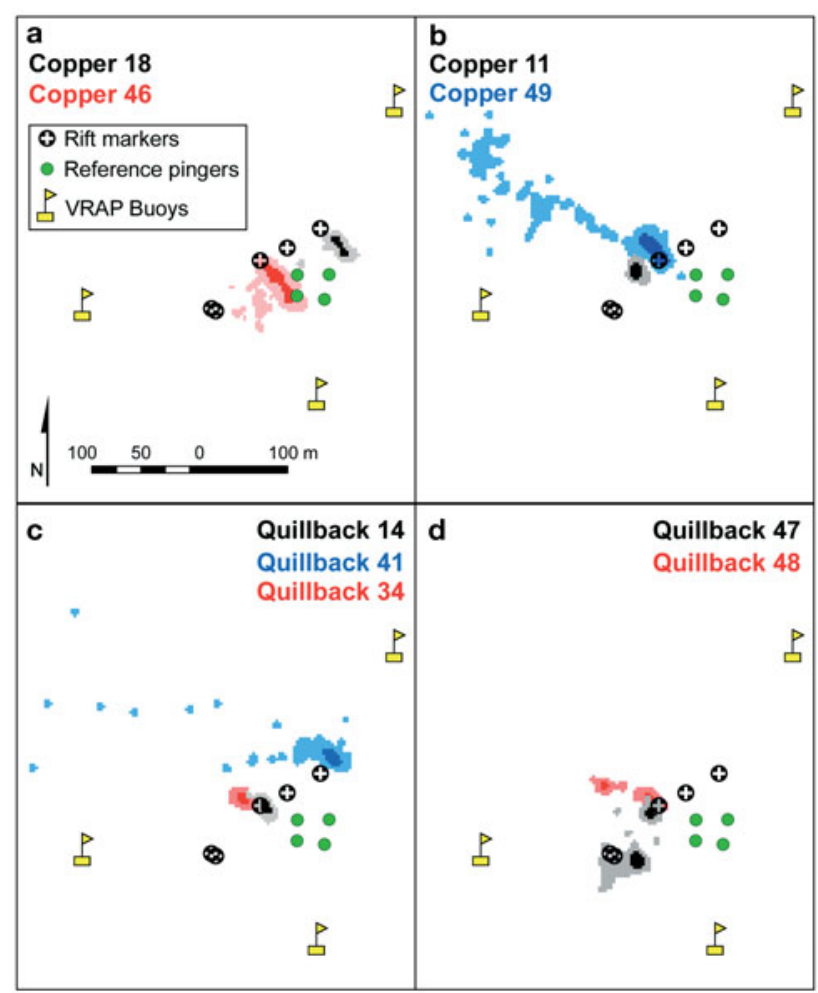

ments to these areas, but along with these daily movements were periods of several days when individuals did not make the daily movement away from the trench. Since these periods of inactivity were not the same, it does not seem likely that they were related to environmental factors (like lunar phase) in a general way across individuals.

Copper and quillback rockfish also showed diel patterns of movement. Unlike the lingcod, which primarily moved to certain areas during the day, the rockfishes showed this behavior both during the day and at night. For example, copper 49 occupied a small area near the ridge at all times (Fig. 5d). However at night it generally moved about $50 \mathrm{~m}$ off from the ridge to more open habitat, and on some nights it wandered up to several hundred meters from its daytime position. The smaller distance excursions do not appear to be partic-

Fig. 4. Sebastes caurinus and S. maliger. Summer (8 wk) home range for the $(\mathrm{a}, \mathrm{b}) 4$ copper and $(\mathrm{c}, \mathrm{d}) 5$ quillback rockfish tagged in the study. For each fish, the darker shade is the $50 \%$ utilization distribution (UD); the lighter shade represents the $95 \%$ UD

Table 2. Ophiodon elongatus, Sebastes caurinus and S. maliger. Summary of home range behaviors, by individual. SL: standard length; Multiple core: multiple core areas; Wandering: extensive movements that occur only during a particular portion of the day, but which are not substantial enough to result in a core area seen only nocturnally or diurnally; Tide: tide during which an individual made tidally related movements. Y: presence of behavior; N: absence of behavior

\begin{tabular}{|c|c|c|c|c|c|c|c|c|c|c|c|}
\hline \multirow[t]{2}{*}{ ID } & \multirow[t]{2}{*}{ SL } & \multirow{2}{*}{$\begin{array}{l}\text { Multiple } \\
\text { core }\end{array}$} & \multicolumn{2}{|c|}{ - Activity space - } & \multirow[t]{2}{*}{ Wandering } & \multirow[t]{2}{*}{ Tide } & \multicolumn{2}{|c|}{$\longrightarrow$ Home range shift -} & \multirow{2}{*}{$\begin{array}{l}\text { Long } \\
\text { absence }\end{array}$} & \multirow{2}{*}{$\begin{array}{l}\text { Winter } \\
\text { presence }\end{array}$} & \multirow{2}{*}{$\begin{array}{l}\text { Winter diel } \\
\text { movements }\end{array}$} \\
\hline & & & Diurnal & Nocturnal & & & Within season & Between seasons & & & \\
\hline \multicolumn{12}{|c|}{ Lingcod } \\
\hline 13 & 63 & & & & & & & & & $\mathrm{Y}$ & \\
\hline 15 & 55 & $\mathrm{Y}$ & $\mathrm{Y}$ & & Y & Flood & & & & & \\
\hline 16 & 57 & $\mathrm{Y}$ & $\mathrm{Y}$ & & $\mathrm{Y}$ & Flood & & & & $\mathrm{Y}$ & $\mathrm{N}$ \\
\hline 17 & 50 & $\mathrm{Y}$ & $\mathrm{Y}$ & & $\mathrm{Y}$ & Flood & $\mathrm{Y}$ & & & & \\
\hline 32 & 47 & $\mathrm{Y}$ & $\mathrm{Y}$ & & $\mathrm{Y}$ & Flood & & & & & \\
\hline 35 & 68 & & $\mathrm{Y}$ & & & Ebb & & $\mathrm{Y}$ & & $\mathrm{Y}$ & \\
\hline 44 & 65 & $\mathrm{Y}$ & & & $\mathrm{Y}$ & Ebb & & & & $\mathrm{Y}$ & $\mathrm{N}$ \\
\hline 741 & 49 & & & & & & & & & $\mathrm{Y}$ & \\
\hline 745 & 45 & & & & & & & & $\mathrm{Y}$ & & \\
\hline \multicolumn{12}{|c|}{ Copper rockfish } \\
\hline 11 & 35 & & & & & & & & & $\mathrm{Y}$ & \\
\hline 18 & 33 & & & & & & & & & $\mathrm{Y}$ & \\
\hline 46 & 36 & & $\mathrm{Y}$ & & & pring ebl & & $\mathrm{Y}$ & & $\mathrm{Y}$ & \\
\hline 49 & 30 & & & $\mathrm{Y}$ & & ring floo & & $\mathrm{Y}$ & & $\mathrm{Y}$ & \\
\hline \multicolumn{12}{|c|}{ Quillback rockfish } \\
\hline 14 & 32 & & & & & & & & & & \\
\hline 34 & 26 & & & & & & & & & $\mathrm{Y}$ & \\
\hline 41 & 29 & & & & & Flood & & & & $\mathrm{Y}$ & \\
\hline 47 & 30 & $\mathrm{Y}$ & $\mathrm{Y}$ & & & Ebb & & & & $\mathrm{Y}$ & $\mathrm{N}$ \\
\hline 48 & 32 & $\mathrm{Y}$ & & $\mathrm{Y}$ & $\mathrm{Y}$ & Flood & & & & $\mathrm{Y}$ & $\mathrm{N}$ \\
\hline
\end{tabular}




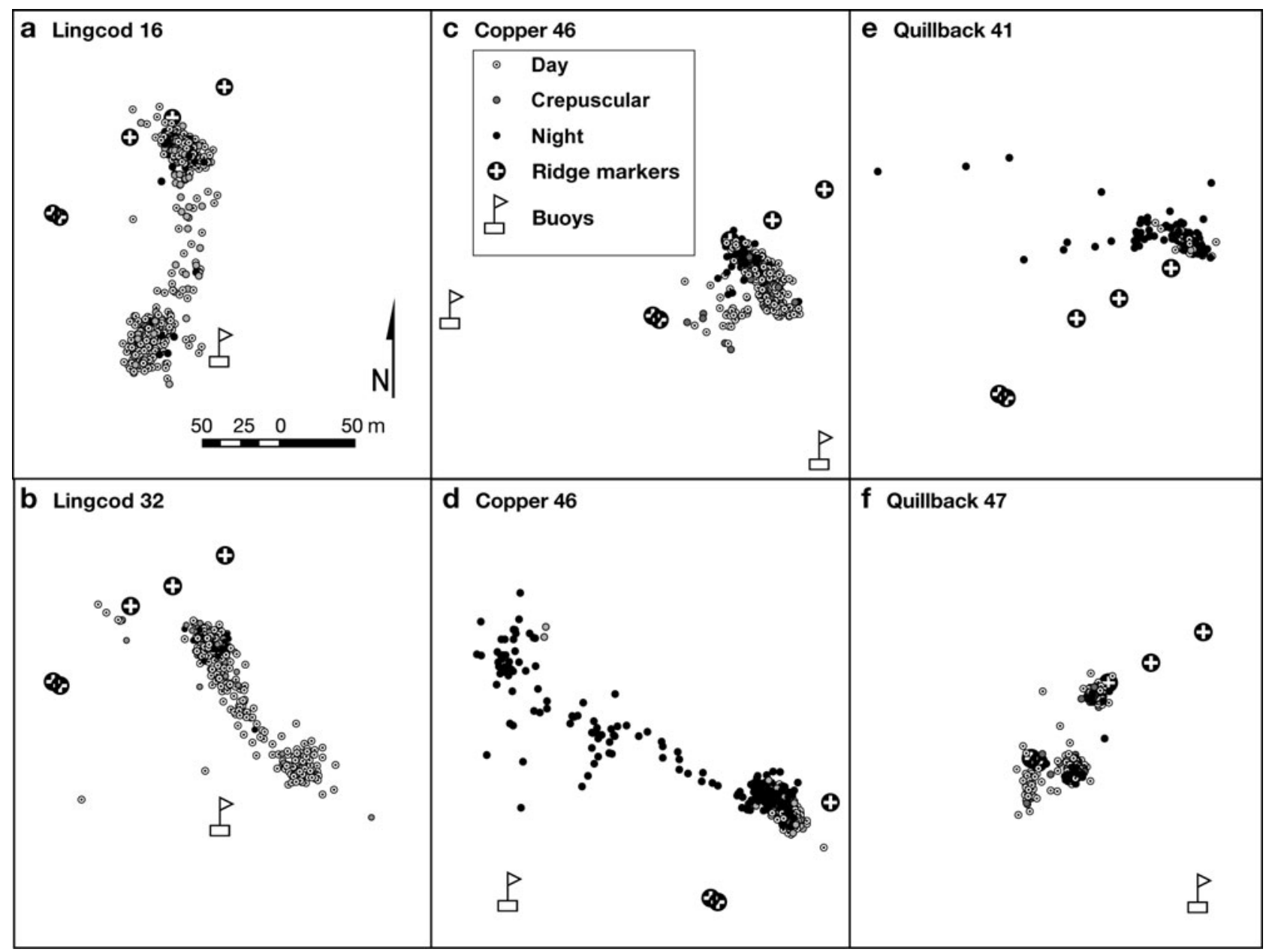

Fig. 5. Ophiodon elongatus, Sebastes caurinus and S. maliger. Examples of diel movement patterns by (a,b) lingcod, (c,d) copper rockfish, and (c,f) quillback rockfish. Symbols represent individual relocations. Ridge markers are included as a reference since not all VRAP buoys are shown

ularly tide-dependent occurring on both flood and ebb tides. The longer distance excursions tended to occur on nocturnal flood tides around the spring tide (Fig. 6d). Copper 46 showed the opposite pattern (Fig. 5c). It occupied an area near the ridge during both night and day, but moved to areas farther from the ridge only during the day (and crepuscular hours to some extent) and at both flood and ebb tides (Fig. 6c,d). Interestingly, this fish frequently made several excursions a day, returning to the ridge area during slack tide. Thus, while copper rockfish did not show multiple core areas, they still showed diel movement patterns similar to the lingcod and quillback. Their space use during these movements was much more diffuse, however.

The quillbacks showed behavior similar to the copper with 2 fish having nocturnal activity spaces and 1 having a diurnal one (Fig. 5e,f). For example, quillback 41 moved away from the ridge at night to another adja- cent area only about $50 \mathrm{~m}$ away (although this does not show up as a separate core area). At other times it also ranged as much as $200 \mathrm{~m}$ from this area. Like copper 49 these long excursions tended to occur on flood tides during the spring tide portion of the tidal cycle (Fig. 6e,f). Also like copper 49, quillback 41 generally occupied an area along the bottom or west side of the ridge in the deeper bowl area. Quillback 48 behaved similarly to quillback 41. Quillback 47 appeared to exhibit the opposite behavior. It occupied 2 core areas during all times of day but moved to another area to the southwest primarily only during daylight hours and on ebb tides during the spring tide portion of the tidal cycle. These fish were approximately the same size (29 and $30 \mathrm{~cm}$ TL respectively). For the nocturnal individuals of both rockfish species, these movement patterns did not appear to be influenced by lunar phase in relation to the spring tide. 
Over longer time periods, movement behavior also varied among individuals. For example, over the course of the $8 \mathrm{wk}$ summer season, lingcod 17 completely shifted its activity space within its summer home range over $100 \mathrm{~m}$ from just east of the ridge to west of the depression to the northwest (Fig. 7a). Lingcod 745 disappeared for several weeks before returning to its original location (Fig. 7b). We cannot determine whether this individual was absent from the study area or concealed in such a way as to prevent its tag from being detected. However, given the length of time during which it was not recorded, the former seem more likely. Quillback 47, which showed diurnal movements earlier in the summer, ceased to make diel movements later in the summer (Fig. 7c). When comparing patterns of movement and areas of occupation in the summer to the winter, several fish (like copper 49 and lingcod 16) ceased to make the diurnal or nocturnal excursions they had made previously (Fig. 8a,b). Some fish, like lingcod 35 shifted their home ranges between summer and winter. In the case of lingcod 35, it shifted its home range approximately $50 \mathrm{~m}$ from the west/lower side of the ridge to the east/upper section (Fig. 8c). Two copper rockfish also moved their home ranges between winter and summer.

\section{DISCUSSION}

\section{Tagging and tracking methodology}

Overall our estimates of home range for lingcod, copper rockfish and quillback rockfish are consistent with previous work showing fairly small home ranges for these fishes, at least at shorter time scales. Our ability to continuously document details of fish behavior revealed enormous variability in the how fish use space and how use of space varies as a function of environmental variables. Given the similar estimates of home range size provided by the VRAP system and other acoustic tracking methodologies (e.g. Matthews 1990c), both appear adequate for the basic estimation of home range size. The continuous monitoring of fish position that the VRAP technology provides, opens up a range of options for the study of behavior much of
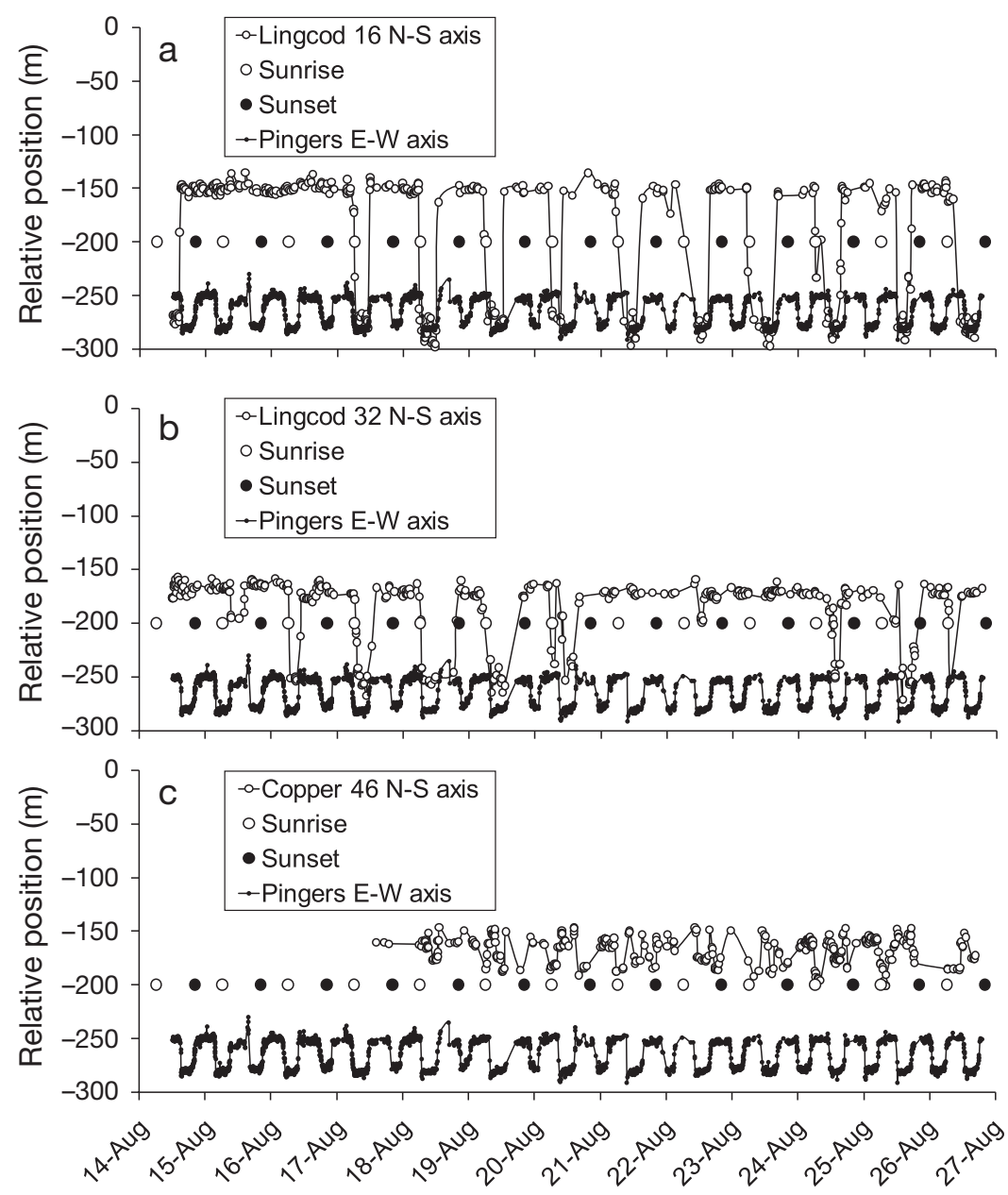

Fig. 6. Ophiodon elongatus, Sebastes caurinus and S. maliger. Examples of fish movement versus time showing $(\mathrm{a}, \mathrm{b}) \operatorname{lingcod},(\mathrm{c}, \mathrm{d})$ copper, and $(\mathrm{e}, \mathrm{f})$ quillback movements in relation to diel and tidal cycles from 14 to 26 Aug 2006. Values on the $y$-axis are relative and represent movement in meters, not actual position within the array. The movement of the fish is shown on either the east-west or north-south axis within the buoy array, depending on the fish's axis of greatest movement from one activity space to another. Fish movement was corrected for buoy movement as described in 'Materials and ( Tagging and tracking methodology'. Time of sunrise (open circle) and sunset (closed circle) is shown as well. The apparent east-west movement of the permanent pingers indicates the tidal cycle. Smaller values on the $y$-axis for the permanent pinger movement indicate flood tide while larger values indicate ebb tide

which may be important both for the design of marine reserves and for addressing behavioral questions such as optimal foraging, predator avoidance, and habitat preference.

\section{Home range size}

Previous movement studies of lingcod have generally focused on longer time periods and larger spatial scales or did not specifically estimate home range size. 

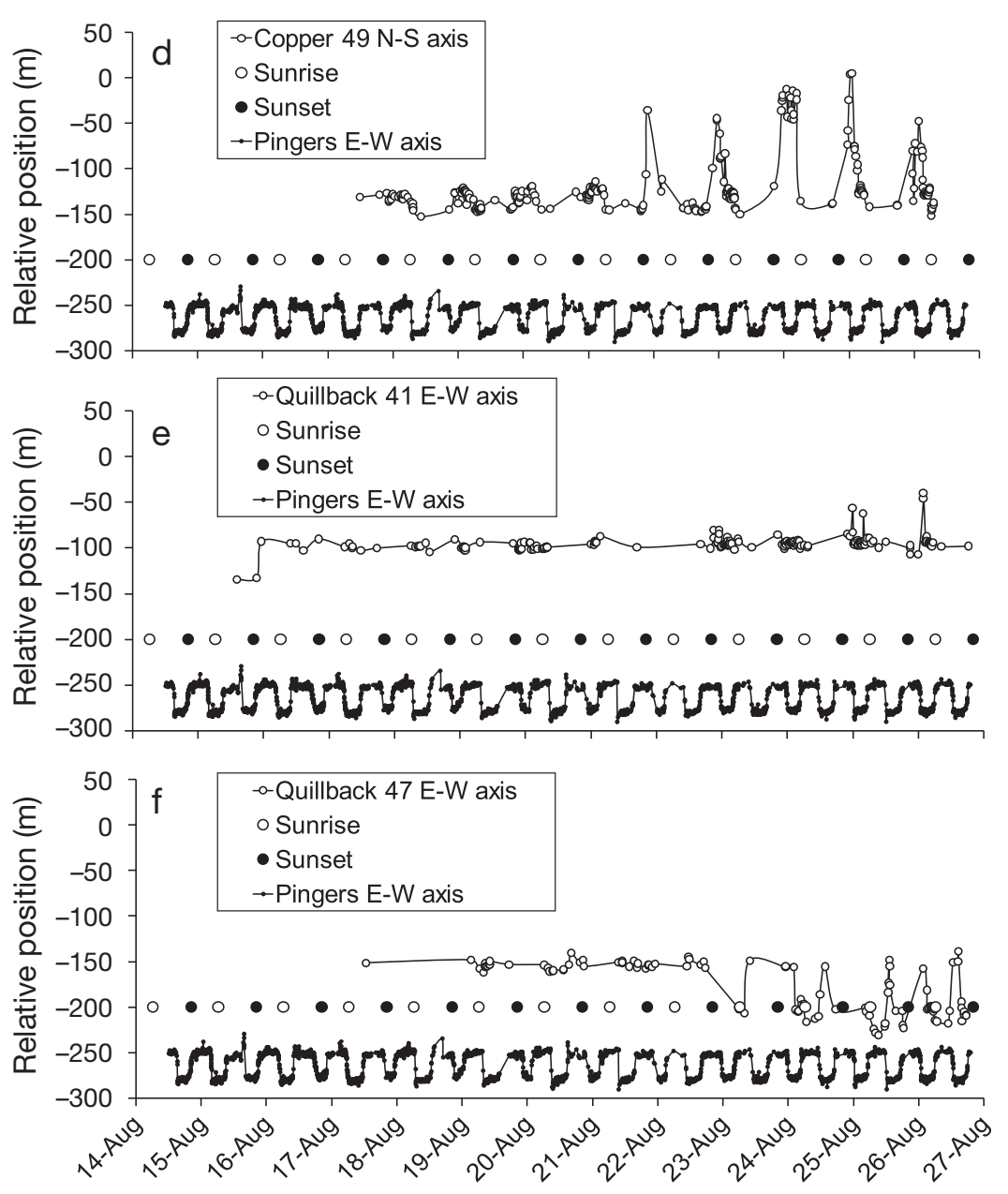

Fig. 6 (continued)

For example mark-recapture studies have shown that over the course of several years most lingcod will remain within approximately $8 \mathrm{~km}$ of their original tagging site, although some will move $50 \mathrm{~km}$ or more (Matthews et al. 1986, Jagielo 1990, Smith et al. 1990), and there may be an overall positive dispersal rate (Smith et al. 1990). Acoustic studies have found that lingcod may leave a particular reef occasionally, but will generally return within 14 d (Starr et al. 2004). Those that are experimentally displaced short distances (several $\mathrm{km}$ ) generally return to their site of capture (Matthews 1992).

For lingcod, there appear to be at least 2 spatial scales on which movement occurs. At a smaller scale, fish have home ranges between 2000 to $3000 \mathrm{~m}^{2}$ on average and may make diel movements within these home ranges (present study). Lingcod disappear from these fairly confined home ranges for periods of several weeks (Starr et al. 2004), and they may disperse to new locations (Jagielo 1990, Starr et al. 2004). Thus their total space use may be quite large over the long term, and the design of a network of MPAs should take into account both the size of individual reserves as well as the distance between them if lingcod management or conservation is one of the primary aims.

For copper and quillback rockfish, our estimates of mean home range size are of the same order of magnitude as those found by Matthews (1990c) for low relief reefs in Puget Sound (ca. $4000 \mathrm{~m}^{2}$ ). Apart from the uplifted ridge through the center of our site, the study area is generally low relief. On high relief reefs, Matthews (1990c) found much smaller home ranges $\left(<10 \mathrm{~m}^{2}\right)$. If one looks more closely at our data, however, there appear to be 2 groups of fish in terms of home range size. Some rockfishes (both copper and quillback) in our study had small home ranges (612 to $783 \mathrm{~m}^{2}$ for the summer data). The other rockfishes had home ranges at least 3 times as large (2394 to 5751 $\mathrm{m}^{2}$ ), with only 1 fish having an intermediate sized home range $\left(1215 \mathrm{~m}^{2}\right)$. Those individuals with large home ranges tended to make diel movements, while the fish with small home ranges tended to remain in the vicinity of the ridge. Thus some of the rockfish use this particular site more like a low relief site while others remain closer to the ridge using the site more like a high relief one. Strikingly, these 2 behaviors in the summer converged in the winter with the mean of all winter home ranges taking an intermediate value $\left(1787 \mathrm{~m}^{2}\right)$. This suggests if there are 2 types of movement behaviors in the summer that are ecological in nature (i.e. alternate foraging strategies, social hierarchies, gender differences), these ecological processes are not at work in winter. Matthews (1990c) did not notice differences in home range or movement with diel phase or current strength, but only monitored 2 fish (1 quillback and 1 copper). Like Matthews (1990c), we did not see a difference in mean home range size at night versus during the day for the rockfishes, although lingcod had larger diurnal home ranges than nocturnal ones in the summer. However for the rockfish, the negative result at the population level occurred because some individuals had larger home ranges during the day while others did at night. Thus variability in behavior among individuals was important. 


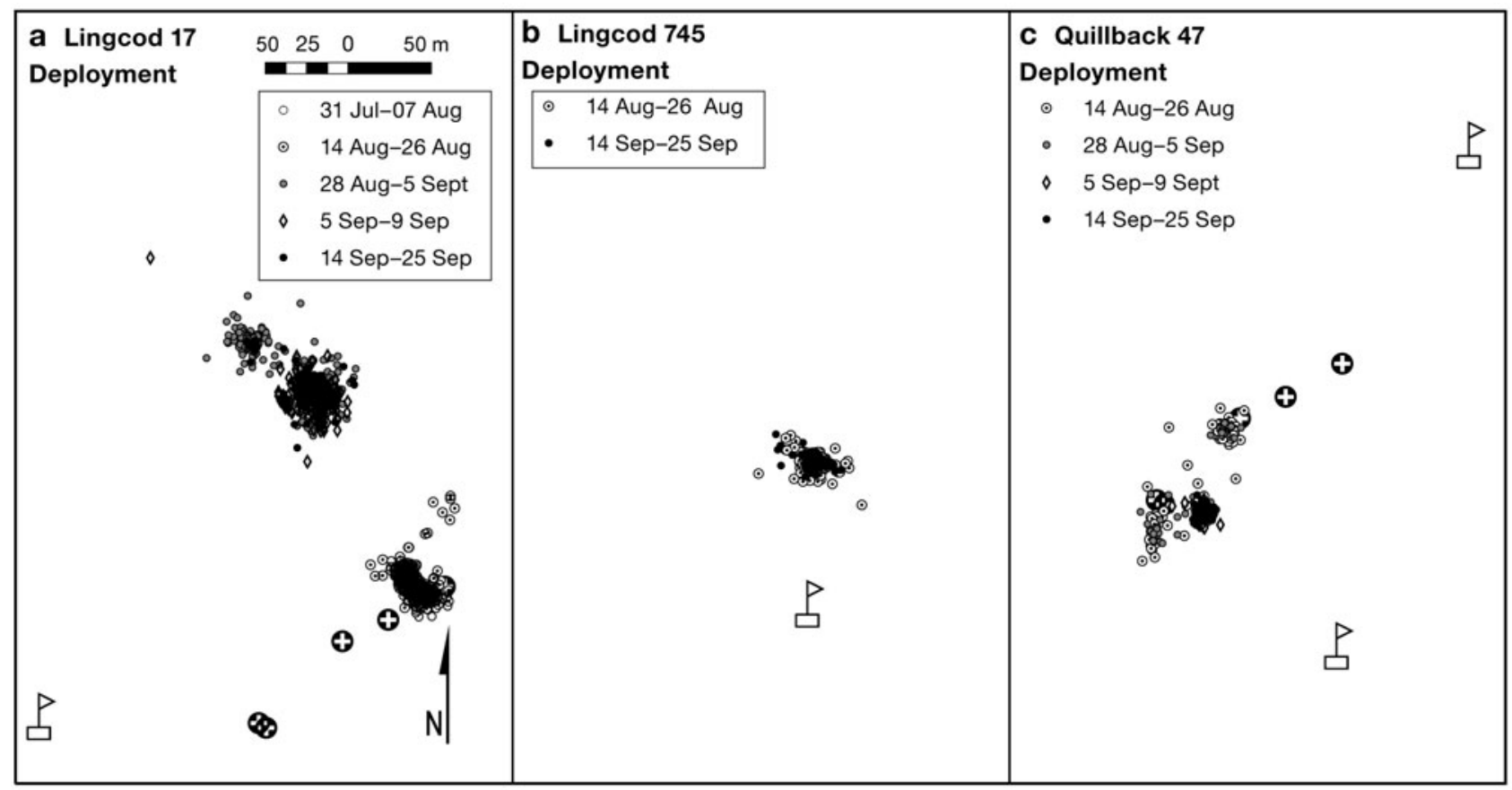

Fig. 7. Ophiodon elongatus, Sebastes caurinus and S. maliger. Examples of home range use within the summer 8 wk sampling period. For dates of the deployments, see panels. (a) Lingcod 17 shifted its home range. (b) Lingcod 745 was absent from its home range for several weeks. (c) Quillback 47 stopped ranging over the summer. Same scale in all panels, symbols as in Fig. 5

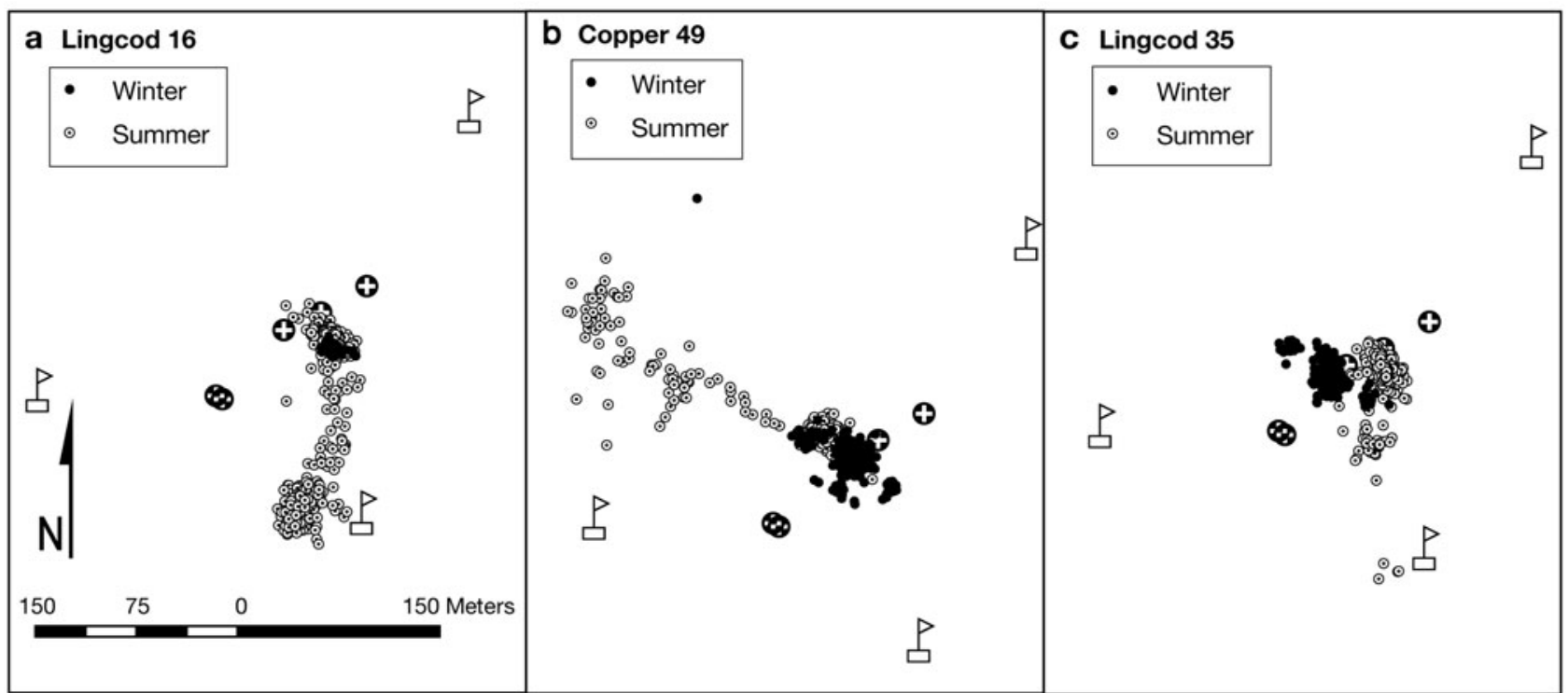

Fig. 8. Ophiodon elongatus, Sebastes caurinus and $S$. maliger. Examples of changes in home range space use between summer and winter sampling periods. (a,b) Individuals that ceased ranging from their core areas; (c) an individual that shifted its home range between summer and winter. Same scale in all panels, symbols as in Fig. 5

\section{Movement behavior}

The wide range of movement behavior and home range size within each of the 3 species is perhaps the most interesting aspect of the study. Much of the space use appears to have a diel pattern with a tidal component. Approximately half of the lingcod occupied a cer- tain portion of their home range exclusively during the day, primarily on the flood tide, although 1 fish made similar movements on the ebb. As a result lingcod had larger diurnal home ranges than nocturnal ones during the summer when these diel movements occurred. Copper and quillback rockfish showed 3 basic patterns. Some fish remained fairly sedentary; some fish 
moved to certain portions of their home range at night on the flood tide; others used certain portions of their home range only during the day ebb tide.

It seems likely that the diel movements are primarily related to feeding, not shelter seeking or reproductive behaviors. The ridge area represents the principle topological structure in the area, and would be the obvious point to seek refuge from predators or strong currents while inactive. Fish that moved tended to move away from the ridge into areas used exclusively at night or during the day (with some crepuscular crossover). In many cases the space use away from the reef was quite diffuse suggesting a more wandering type of behavior related to foraging or mate searching (although this seems unlikely for the time of year) not sheltering in place.

We do not have data on the distribution of food resources around our study site, so we cannot give a concrete explanation as to why the fishes would leave the ridge area to feed. In Puget Sound, lingcod eat large amounts of sand lances (Ammodytidae) and herring (Clupeidae) as well as rockfish (Scorpaenidae) depending upon the size of the lingcod (Beaudreau \& Essington 2007). Individuals that made the longer movements of 150 to $200 \mathrm{~m}$ may have done so to better access pelagic food resources. Copper and quillback rockfish tend to feed near the bottom and their diets include shrimps, gammarid amphipods, and fishes to some extent. Benthic food resources may be more plentiful distant from the ridge due to lower overall grazing pressure, and higher food availability may offset higher predation risk due to lack of shelter. Off the coast of Alaska and British Columbia, these rockfish also consume sand lances and herring, and quillback may make foraging excursions into the water column (Love et al. 2002), so these rockfish may also be accessing pelagic food resources.

Other authors have noted movements related to sheltering in salema Salpa salpa (Jadot et al. 2006), blue rockfish $S$. mystinus (Jorgensen et al. 2006) and sheephead Semicossyphus pulcher (Topping et al. 2005), and reproduction in the sparid Pagrus auratus (Parsons et al. 2003). For species like blue rockfish (Jorgensen et al. 2006) and sheephead (Topping et al. 2005) all individuals showed the same diel patterns of movement and home range use unlike the rockfish here which showed a range of behaviors.

\section{Individual behavior and MPA design}

Quantifying the typical home range size of a fish has obvious applications to the design of MPAs. Likewise, understanding the individual variation in space use and movement behavior has implications regard- ing spillover and edge effects (Zeller \& Russ 1998, Kramer \& Chapman 1999, Cole et al. 2000). For example, understanding what proportion of individuals move seasonally can help to estimate fishing mortality and the effectiveness of the reserves (Willis \& Millar 2005). Within seasons, lingcod used fairly small home ranges for periods of several months. However, some individuals appear to make excursions from these localized areas for periods of up to a month after which they may disperse to new locations or return to their original home range (this study, Jagielo 1990, Starr et al. 2004). How common this type of behavior is has relevance for determining how much spillover (or just general movement out of reserves) may occur. Those fish that make the type of diel/tidal movements seen in our study are also potentially more susceptible to crossing reserve boundaries. When and how frequently they do so, may determine what the consequences are. For example, many of the lingcod in this study moved away from the ridge area on the morning flood tide, which would likely make them more susceptible to fishing than individuals that make nocturnal movements presuming that fishing pressure is generally lower at night.

\section{CONCLUSIONS}

Ecologically-based management of marine systems requires generalizations about nature, and this process of simplifying the complex natural world depends critically on a keen sense of natural history (Dayton 2003). Indeed, the essential challenge in translating basic ecological observations into management is weeding out less relevant information, while ensuring that management takes into account those critical processes that produce ecological structure. Although it might be tempting to base management (e.g. MPAs) on average home ranges of species, such an approach is insensitive to the variability of behavior expressed within and among different species of groundfish. Management of species such as those we investigated here rest not only on understanding average behavior, but also on understanding the processes generating variability in behavior (Gaines \& Denny 1993). The high frequency behavioral observations reported here provide the level of observation necessary to develop meaningful hypotheses that can be tested experimentally. It is only with this second level of understanding that will allow us to make reasonable predictions as to how species will respond to environmental perturbations, such as climate change or habitat-loss, or to specific management strategies, such as the implementation of marine reserves or other spatial or temporal strategies for management and conservation. While the arena of 
resource management often requires us to simplify complex systems, our results illustrate that such simplification will be difficult, and will depend ultimately on detailed behavioral data. As Dayton (2003) noted, along the path to science-based resource management, when it comes to natural history, there can be no shortcuts.

Acknowledgements. We thank 3 anonymous reviewers, J. Samhouri, D.E. Hamm, B. Berejikian, J. Lee and T. Willis for comments on the manuscript C. Harvey, K. Fricke and J. Hayden-Spear provided diving assistance. Navigational Response Team 3 provided the soundings data for the multibeam map of the site. This project could not have been completed without the help of G. and S. Parmelee who provided power and shelter for our radio and computer equipment. We also thank G. Gygax, S. M. Sechi, G. Stafford, M. Miller, and N. R. Crosby. G. Noll, M. Dora, D. Nuuhiwa, E. Aika and K. Slater provided inspiration along the way.

\section{LITERATURE CITED}

Allen MJ, Smith GB (1988) Atlas and zoogeography of common fishes in the Bering Sea and northeastern Pacific. NOAA Tech Rep 66, National Marine Fisheries Service, Seattle, WA

Anderson DJ (1982) The home range: a new nonparametric estimation technique. Ecology 63:103-112

Austin D, Bowen WD, McMillan JI (2004) Intraspecific variation in movement patterns: modeling individual behaviour in a large marine predator. Oikos 105:15-30

Beaudreau AH, Essington TE (2007) Spatial, temporal, and ontonogenetic patterns of predation on rockfishes by lingcod. Trans Am Fish Soc 136:1438-1452

Bowman AW (1985) A comparative study of some kernelbased nonparametric density estimators. J Stat Comp Sim 21:313-327

Burt WH (1943) Territoriality and home range concepts as applied to mammals. J Mammal 24:346-352

Cole RG, Villouta E, Davidson RJ (2000) Direct evidence of limited dispersal of reef fish Paracpercis colias (Pinguipedidae) within a marine reserve and adjacent fished waters. Aquat Conserv 10:421-436

Dayton PK (2003) The importance of the natural sciences to conservation. Am Nat 162:1-13

Eschmeyer WN, Herald ES, Hammann H (1983) A field guide to Pacific coast fishes of North America. Houghton Mifflin Company, Boston, MA

Fretwell SD (1972) Populations in a seasonal environment. Princeton Univ. Press, Princeton, NJ

Fretwell SD, Lucas HL (1969) On territorial behavior and other factors influencing habitat distribution in birds. I. Theoretical development. Acta Biotheor 19:16-36

Gaines SD, Denny MW (1993) The largest, smallest, highest, lowest, longest and shortest: extremes in ecology. Ecology 74:1677-1692

Henningsen AD (1994) Tonic immobility in 12 elasmobranchs: use as an aid in captive husbandry. Zoo Biol 13:325-332

> Holland KN, Wetherbee BM, Lowe CG, Meyer CG (1999) Movements of tiger sharks (Galeocerdo cuvier) in coastal Hawaiian waters. Mar Biol 134:665-673

> Jadot C, Donnay A, Colas ML, Cornet Y, Bégout Anras ML (2006) Activity patterns, home-range size, and habitat uti- lization of Sarpa salpa (Teleostei: sparidae) in Mediterranean waters. ICES J Mar Sci 63:128-139

Jagielo TH (1990) Movement of tagged lingcod Ophiodon elongatus at Neah Bay, Washington. Fish Bull 88:815-820

Jorgensen SJ, Kaplan DM, Klimley AP, Morgan SG, O'Farrell MR, Botsford LW (2006) Limited movement in blue rockfish Sebastes mystinus: internal structure of home range. Mar Ecol Prog Ser 327:157-170

Katajisto J, Moilanen A (2006) Kernel-based home range method for data with irregular sampling intervals. Ecol Model 194:405-413

Kramer D, Chapman M (1999) Implications of fish home range size and relocation for marine reserve function. Environ Biol Fishes 55:65-79

Lindholm J, Auster PJ, Knight A (2007) site fidelity and movement of adult Atlantic cod Gadus morhua at deep boulder reefs in the western Gulf of Maine, USA. Mar Ecol Prog Ser 342:239-247

Littell RC, Miliken GA, Stroup WW, Wolfinger RD (1996) SAS system for mixed models, Vol. SAS Institute Inc, Cary, NC

Love MS, Yoklavich M, Thorsteinson L (2002) The rockfishes of the Northeast Pacific. University of California Press, Berkley and Los Angeles

> Lowe CG, Topping DT, Cartamil DP, Papastamatiou YP (2003) Movement patterns, home range and habitat utilization of adult kelp bass Paralabrax clathratus in a temperate notake marine reserve. Mar Ecol Prog Ser 256:205-216

Matthews KR (1990a) A comparative study of habitat use by young-of-the-year subadult and adult rockfishes on four habitat types in central Puget Sound. Fish Bull 88: $223-240$

> Matthews KR (1990b) An experimental study of the habitat preferences and movement patterns of copper quillback and brown rockfishes Sebastes spp. Environ Biol Fishes 29:161-178

- Matthews KR (1990c) A telemetric study of the home ranges and homing routes of copper and quillback rockfishes on shallow rocky reefs. Can J Zool 68:2243-2250

Matthews KR (1992) A telometric study of the home ranges and homing routes of lingcod Ophiodon elongatus on shallow rocky reefs off Vancouver Island, British Columbia. Fish Bull 90:784-790

Matthews KR, Miller BS, Quinn TP (1986) Movement studies of nearshore demersal fishes in Puget Sound. In: Melteff BR (ed) Proc Int Rockfish Symp. University of Alaska, Anchorage, p 63-72

McCullagh CE, Searle RS (2001) Generalized, linear, and mixed models. John Wiley \& Sons, New York

Morgan IE, Kramer DL (2004) The social organization of adult blue tangs, Acanthurus coeruleus, on a fringing reef, Barbados, West Indies. Environ Biol Fishes 71:261-273

O'Dor RK, Andrade Y, Webber DM, Sauer WHH, Roberts MJ, Smale MJ, Voegeli FM (1998) Applications and performance of radio-acoustic positioning and telemetry (RAPT) systems. Hydrobiologia 371-372:1-8

Parsons DM, Babcock RC, Hankin RKS, Willis TJ, Aitken JP, O'Dor RK, Jackson GD (2003) Snapper Pagrus auratus (Sparidae) home range dynamics: acoustic tagging studies in a marine reserve. Mar Ecol Prog Ser 262:253-265

Smith BD, McFarlane GA, Cass AJ (1990) Movements and mortality of tagged male and female lingcod in the Straight of Georgia, British Columbia. Trans Am Fish Soc 119:813-824

> Starr RM, O'Connell V, Ralston S (2004) Movements of lingcod (Ophiodon elongatus) in southeast Alaska: potential for increased conservation and yield from marine reserves. Can J Fish Aquat Sci 61:1083-1094 
Topping DT, Lowe CG, Caselle JE (2005) Home range and habitat utilization of adult California sheephead, Semicossyphus pulcher (Labridae), in a temperate no-take marine reserve. Mar Biol 147:301-311

VEMCO (2003) VEMCO Limited VRAP hardware manual. VEMCO, Shad Bay, NS

Verbeke G, Molenberghs G (1997) Linear mixed models in practice: a SAS-oriented approach. Springer, New York

WDFW (2007) Fishing in Washington: sportfishing rules 2007/

2008 Pamphlet edition. Washington Department of Fish and Wildlife, Olympia, WA

Wells RMG, McNeil H, MacDonald JA (2005) Fish hypnosis:

Editorial responsibility: Jon Hare,

Narragansett, Rhode Island induction of an atonic immobility reflex. Mar Freshwat Behav Physiol 38:71-78

Willis TJ, Millar RB (2005) Using marine reserves to estimate fishing mortality. Ecol Lett 8:47-52

Willis TJ, Parsons DM, Babcock RC (2001) Evidence for longterm site fidelity of snapper (Pagrus auratus) within a marine reserve. NZ J Mar Freshw Res 35:581-590

Worton BJ (1989) Kernel methods for estimating the utilization distribution in home-range studies. Ecology 70:164-168

Zeller DC, Russ GR (1998) Marine reserves: patterns of adult movement of the coral trout (Plectropomus leopardus [Serranidae]). Can J Fish Aquat Sci 55:917-924

Submitted: May 20, 2008; Accepted: January 14, 2009

Proofs received from author(s): March 30, 2009 